
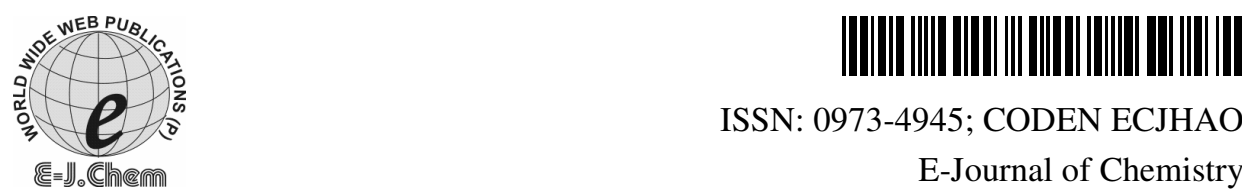

ISSN: 0973-4945; CODEN ECJHAO

http://www.e-journals.net

\title{
Liquid Chromatography/Tandem Mass Spectrometry for the Simultaneous Determination of Alverine and its Metabolite, Monohydroxy Alverine, in Human Plasma: Application to a Pharmacokinetic Study
}

\author{
RAHUL C. GAVHANE, KETAN K. NERURKAR, ASHOK M. KALAMKAR, \\ MITESH R. PATIL, SATISH G. PINGALE and PRAFULLAKUMAR KULKARNI
}

\author{
Drug Monitoring Research Institute \\ Rabale, Navi Mumbai-400701, Maharashtra, India \\ *Department of Chemistry \\ Yeshwant College, Nanded-431605, Maharashtra, India \\ rahul_cg@rediffmail.com
}

Received 8 February 2010; Accepted 7 April 2010

\begin{abstract}
A rapid and sensitive LC-MS-MS method for the determination of alverine (ALV) and its major metabolite, monohydroxy alverine (MHA), in human plasma using imipramine as an internal standard was developed and validated. The analytes were extracted from $0.5 \mathrm{~mL}$ aliquots of human plasma by solid phase extraction, using oasis cartridge. Chromatographic separation was carried on Thermo Gold $\mathrm{C} 18$ column $(50 \times 4.6 \mathrm{~mm}, 5 \mu)$ at $30{ }^{\circ} \mathrm{C}$, with isocratic mobile phase, a flow rate of $0.4 \mathrm{~mL} / \mathrm{min}$ and a total run time of $3.5 \mathrm{~min}$. Detection and quantification were performed using a mass spectrometer in the selected reaction-monitoring mode with positive electrospray ionization at $\mathrm{m} / \mathrm{z} 282.3 \rightarrow$ 91.11 for alverine, $\mathrm{m} / z .298 .3 \rightarrow 106.9$ for mono-hydroxy-alverine, and $\mathrm{m} / z 281.0$ $\rightarrow 86.0$ for internal standard (IS) respectively. This assay was linear over a concentration range of $0.060-10 \mathrm{ng} / \mathrm{mL}$ with a lower limit of quantification of $0.060 \mathrm{ng} / \mathrm{mL}$ for both alverine and monohydroxy alverine. The coefficient of variation for the assay precision were $<9.18 \%$ and $<8.44 \%$, the accuracy were $>104.66 \%$ and $>100.38 \%$ for alverine and monohydroxy alverine respectively. This method was successfully applied to a pharmacokinetic study after oral administration of alverine citrate $60 \mathrm{mg}$ capsule in healthy male subjects.
\end{abstract}

Keywords: Alverine, Monohydroxy alverine, LC-MS-MS, Pharmacokinetic study.

\section{Introduction}

Alverine (Figure 1), $N$-methyl- $N$-(3-phenylpropyl)benzenepropanamine, is a common used smooth muscle relaxant agent ${ }^{1}$ with molecular weight of around 281.4. Alverine citrate 
(Spasmonal, Norgine, Harefield, Middlesex, UK) is currently used as an antispasmodic in irritable bowel syndrome and dysmenorrhoea ${ }^{2}$. Alverine (ALV) was shown to inhibit spontaneous electrical activity and nervous control of the proximal colon of the rabbit in vivo ${ }^{3}$. It was also found to decrease the sensitivity of the intestinal mechanoreceptors in response to chemical stimulation in anaesthetized cats ${ }^{4}$ and reduce 5-hydroxytryptamine $1 \mathrm{~A}$ receptor-mediated rectal hypersensitivity in the rat ${ }^{5}$. However, the exact mechanisms of ALV's inhibitory action are still not clear, due to the lack of information of its effects on isolated smooth muscle in vitro. In accordance with previous results of double-blind, randomized, placebo controlled trial conducted, indicated that ALV citrate is no better than placebo at relieving the symptoms of irritable bowel syndrome ${ }^{6}$. Arhan in his case study has discussed how ALV citrate induced hepatitis?

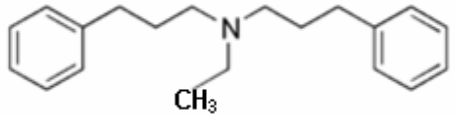

(A)

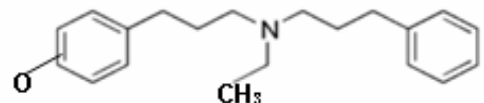

(B)

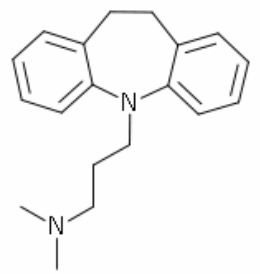

(C)

Figure 1. Structures of (A) Alverine; (B) Monohydroxy alverine and (C) Imipramine

In recent research, Hayase ${ }^{2}$ investigated the mechanisms underlying the paradoxical ability of the antispasmodic, alverine, to enhance spontaneous activity in smooth muscles while suppressing evoked activity. ALV is likely to inhibit the inactivation of Ca channels and increase the $\mathrm{Ca}$ influx during individual action potentials. However they have concluded that the further research has to be carried out for assessing the therapeutic potential of ALV to treat detrusor smooth muscle dysfunction ${ }^{5}$.

There is only one reported ${ }^{8}$ article on quantification of ALV and one of its hydroxy metabolite, para-hydroxy alverine (PHA) in human plasma. The lower limit of quantification (LLOQ) and run time for this method was $0.1 \mathrm{ng} / \mathrm{mL}$ and $4.0 \mathrm{~min}$ respectively and was analyzed on API 5000 LC-MS-MS.

As an alternative, we have developed and validated a new liquid chromatographic/ tandem mass spectrometric (LC-MS-MS) method for determination of the concentration of ALV and MHA in human plasma. The advantages of this method include improved sensitivity $(0.060 \mathrm{ng} / \mathrm{mL})$, simpler pretreatment, shorter separation time $(3.5 \mathrm{~min})$ and high specificity for quantification of ALV and its active metabolite MHA in human plasma on API 4000 LC-MS-MS. The developed and validated method was applied for bioequivalence study.

\section{Experimental}

ALV reference standard (99.50\% of purity) and MHA reference standard (99.50\% of purity) were obtained from Cadila Healthcare (Ahmedabad, India) and internal standard Imipramine (IS, $100.1 \%$ of purity) was purchased from Sigma-Aldrich (Bangalore, India). HPLC grade methanol and acetonitrile were purchased from J. T.Baker (Mumbai, India). All other 
chemicals and solvents were of the highest analytical grade available. Drug-free human plasma with CPDA as an anticoagulant was obtained from healthy subjects that had previously signed a consent form and was stored at $-20{ }^{\circ} \mathrm{C}$ prior to use. Oasis HLB cartridges were obtained from Oasis Mumbai, India. The subject samples obtained post study conduction was also kept stored at $-20{ }^{\circ} \mathrm{C}$ to maintain the integrity of the matrix.

\section{Analytical system}

The plasma ALV and MHA concentrations were quantified using a SCIEX API 4000 LCMS-MS system (Applied Biosystems, Thane, India), equipped with an electrospray ionization interface used to generate positive ions $[\mathrm{M}+\mathrm{H}]^{+}$. The analytes were separated on reversed phase column (Thermo Gold $\mathrm{C} 18,50 \times 4.6 \mathrm{~mm} ; 5 \mu$ particle size; Thermo Scientific, India) with an isocratic mobile phase consisting of $5 \mathrm{mM}$ ammonium formate $(\mathrm{pH} 3.5)$ and acetonitrile $(15: 85, \mathrm{v} / \mathrm{v})$. The column and autosampler temperature were maintained at $30{ }^{\circ} \mathrm{C}$ and $10{ }^{\circ} \mathrm{C}$ respectively. The mobile phase was eluted at $0.4 \mathrm{~mL} / \mathrm{min}$ using a Shimadzu series UFLC system (Shimadzu, Corporation, Kyoto, Japan).

The optimized ion spray voltage and temperature were set at $5500 \mathrm{~V}$ and $500{ }^{\circ} \mathrm{C}$. The typical ion source parameters, viz., declustering potential, collision energy, entrance potential and collision cell exit potential were 80, 40, 10 and $9 \mathrm{~V}$ for ALV; 100, 42, 10 and $9 \mathrm{~V}$ for MHA; 80, 52, 10 and $9 \mathrm{~V}$ for the IS respectively. Nitrogen gas was used for the nebulizer gas, curtain gas and collision-activated dissociation gas, which were set at 40, 20 and 9 psi respectively. Quantification was performed by selected reaction monitoring of the protonated precursor ion and the related product ion for ALV and MHA using the internal standard (IS) method with peak area ratios and a linear least-squares regression curve with a weighting factor of $1 / \mathrm{x}^{2}$.

The mass transition used for ALV, MHA and the IS were $m / z 282.3 \rightarrow 91.11,298.3 \rightarrow$ 106.9 and $281.0 \rightarrow 86.0$ respectively, with a dwell time of 200 millisecond transition. Quadrupoles Q1 and Q3 were set on unit resolution (Figures 2, 3 and 4). The analytical data were processed by analyst software (Version 1.4.2; applied bioystems).

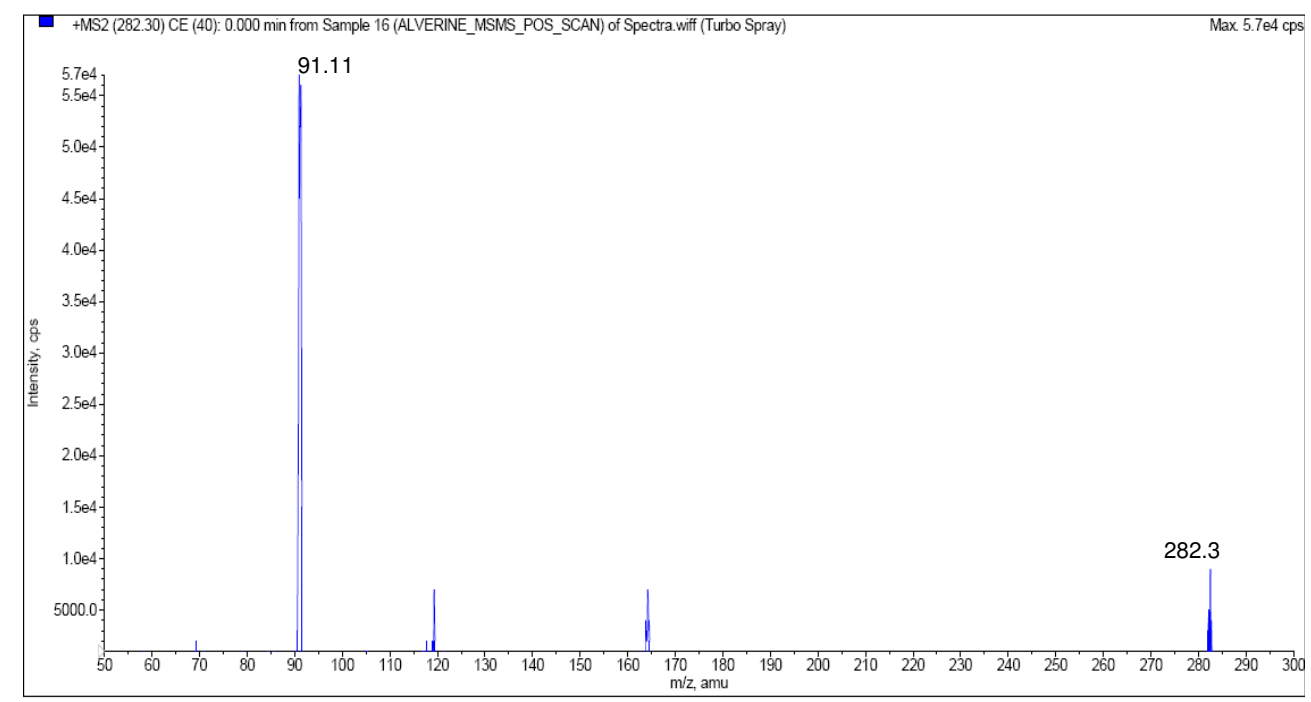

Figure 2. Product ion mass spectra of the $[\mathrm{M}+\mathrm{H}]^{+}$ions of ALV 


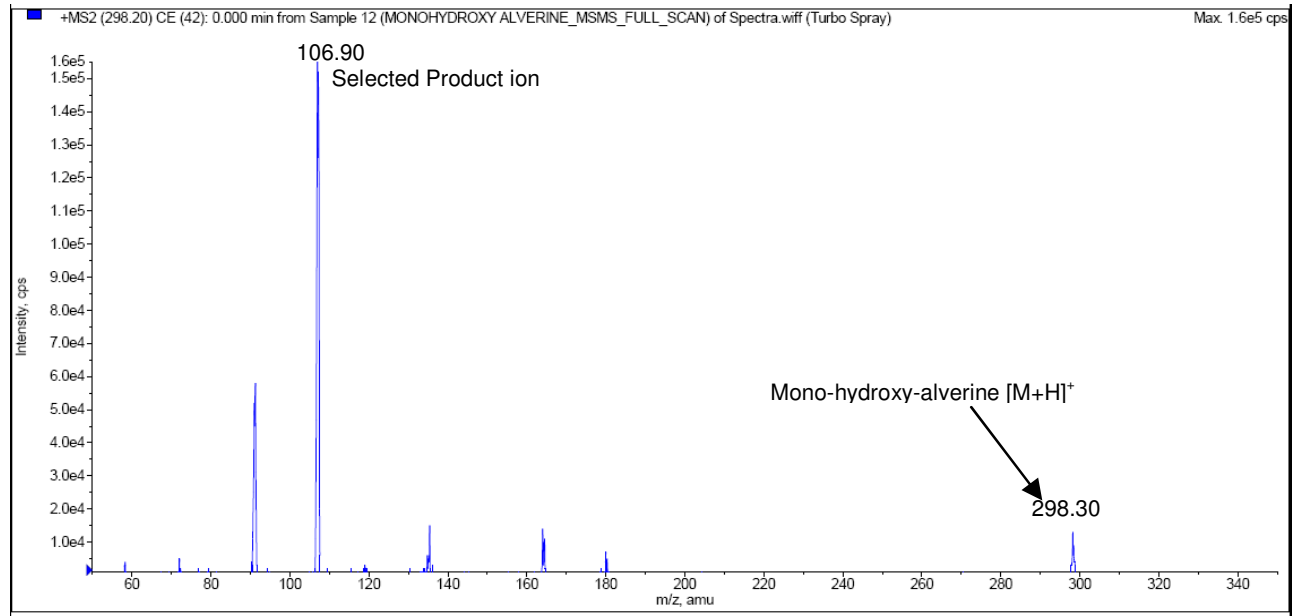

Figure 3. Product ion mass spectra of the $[\mathrm{M}+\mathrm{H}]^{+}$ions of MHA

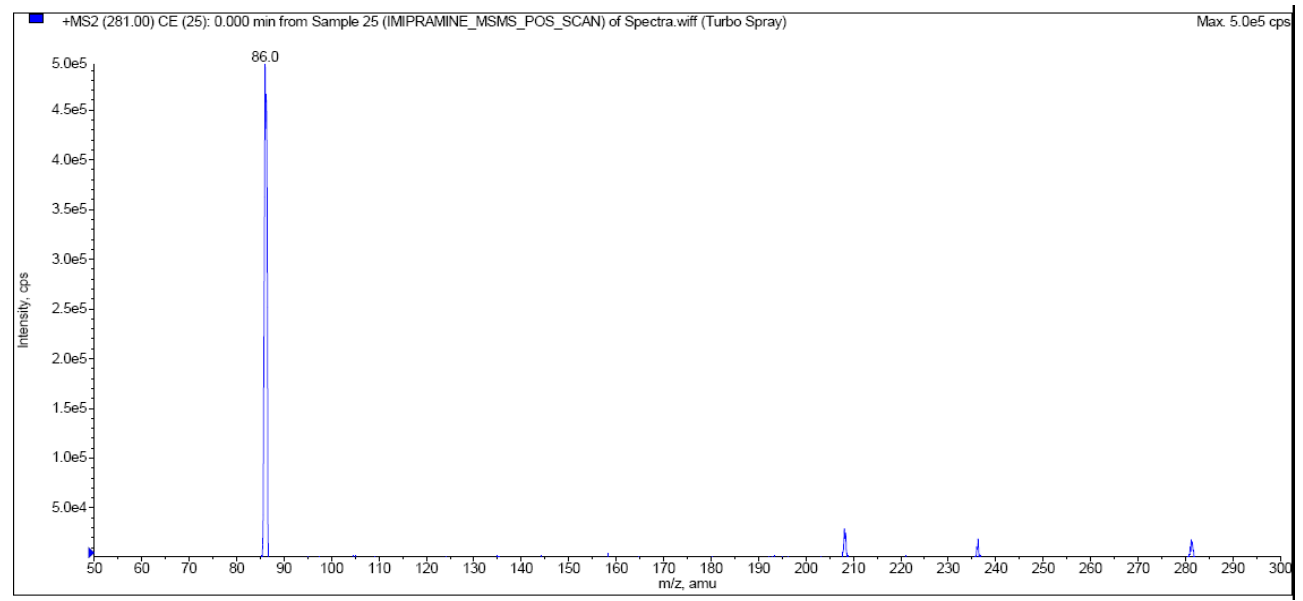

Figure 4. Product ion mass spectra of the $[\mathrm{M}+\mathrm{H}]^{+}$ions of IS

\section{Preparation of standard and quality control samples}

Two separate stock solutions of ALV (as a free salt), MHA and one stock solution of IS were prepared by dissolving $1 \mathrm{mg} / \mathrm{mL}$ of each respectively, in methanol. The IS stock solution was further diluted to $400 \mathrm{ng} / \mathrm{mL}$ in diluent for routine use. The stock solution of ALV and MHA were serially diluted with diluent (methanol: distilled water 50:50). Calibration standards were prepared by spiking $0.5 \mathrm{~mL}$ of blank human plasma with working standard solutions of ALV and MHA. The effective concentrations in standard plasma samples were $0.061,0.122,0.255,1.019,2.037,4.075,6.112,8.150,10.187 \mathrm{ng} / \mathrm{mL}$ for ALV and $0.066,0.133,0.276,1.105,2.210,4.421,6.631,8.842,11.052 \mathrm{ng} / \mathrm{mL}$ for MHA. The quality control samples (QC's) containing $0.184,5.097,7.646 \mathrm{ng} / \mathrm{mL}$ for ALV (low, middle and high quality control concentrations) and $0.199,5.519,8.278 \mathrm{ng} / \mathrm{mL}$ for MHA (low, middle and high quality control concentrations). The standards and quality control samples were used to evaluate the intra and inter-day precision and accuracy of the method. All prepared plasma samples were stored in deep freezer (Sanyo, Japan) at $-20{ }^{\circ} \mathrm{C}$ and all stock solutions were stored at $2-8{ }^{\circ} \mathrm{C}$ in refrigerator. 


\section{Plasma sample preparation}

To a $0.5 \mathrm{~mL}$ aliquot of plasma sample, $20 \mu \mathrm{L}$ of IS $(400 \mathrm{ng} / \mathrm{mL})$ was added. After vortexing, the sample mixture was loaded onto an Oasis HLB $30 \mathrm{mg} 1 \mathrm{cc}$ cartridge that was preconditioned with $1 \mathrm{~mL}$ of methanol followed by $1 \mathrm{~mL}$ of $5 \mathrm{mM}$ ammonium formate (pH 3.5). The extraction cartridge was washed with $1 \mathrm{~mL}$ of distilled water followed by $5 \%$ methanol. Both the analytes and IS were eluted in $0.5 \mathrm{~mL}$ of mobile phase. $15 \mu \mathrm{L}$ of eluant was injected into the API 4000 LC-MS-MS system.

\section{Characterization of the product ions using tandem mass spectrometry}

One micromolar ALV, MHA and IS solutions were separately scanned into mass spectrometer at a flow rate of $10 \mu \mathrm{L} / \mathrm{min}$, to characterize the product ions of each compound. The precursor ions $[\mathrm{M}+\mathrm{H}]^{+}$and the pattern of fragmentation were monitored using the positive ion mode. The major peaks observed in the MS-MS scan were used to quantify ALV, MHA and IS.

\section{Method validation}

The validation parameters were specificity, linearity, selectivity, accuracy, precision and matrix effect of the assay and the recovery and stability in human plasma, according to the US Food and Drug Administration guidance for the validation of bioanalytical methods ${ }^{9}$.

\section{Selectivity}

The method specificity was evaluated by screening six lots of blank human plasma, one lot each of heamolysed and lipemic plasma from healthy donors for assessment of potential interference with endogenous substances at the retention time of ALV, MHA and IS.

\section{Linearity and $L L O Q$}

Calibration curves were determined by plotting the peak area ratio (y) of ALV or MHA to the IS versus the nominal concentration $(x)$ of ALV or MHA, respectively. The calibration curves were constructed by weighted $\left(1 / \mathrm{x}^{2}\right)$ least square linear regression.

The LLOQ is defined as the lowest concentration on the calibration curve, it was validated using LLOQ sample for which an acceptable accuracy (RE) within $\pm 20 \%$ and a precision (RSD) below $20 \%$ were obtained.

\section{Precision and accuracy}

Intra and inter-day accuracy and precision for this method were determined at three different concentration levels on three different validation days. The validation run consist of one calibration curve and six replicates of each LOQ (limit of quantification), LQC (lower quality control), MQC (middle quality control), HQC (high quality control) and ULOQ (upper limit of quantification) levels. The percentage accuracy was expressed as (mean observed concentration) / (nominal concentration) $\times 100$ and the precision was expressed by the relative standard deviation (\%RSD).

\section{Extraction recovery and matrix effect}

The extracted recovery of ALV, MHA and IS were determined by calculating the peak area obtained from blank plasma samples spiked with analyte and IS after extraction with those from un-extracted samples, to which analytes and IS was added.

The matrix effect experiments were carried out by extracting blank plasma from six different sources, eluting the final extract in mobile phase. Lower and higher quality control 
concentrations with IS were spiked respectively. These are post spiked samples and all the assay were performed in duplicate. Mean, standard deviation (SD) and relative standard deviation (\% RSD or \% CV) of the peak area ratio of analytes and internal standard of post spiked samples at each LQC and HQC level was calculated.

\section{Stabilities}

The stability of ALV and MHA in human plasma was assessed by analyzing spiked six replicates of lower and higher concentrations respectively, of ALV and MHA, under following conditions; after short term storage, long term storage at $-20{ }^{\circ} \mathrm{C}$, three freeze thaw cycle, bench top stability, auto-sampler stability, coolant stability, wet extract stability and re-injection reproducibility. The concentrations obtained were compared with the nominal values of the QC samples. The stabilities of the stock solution of ALV, MHA and IS were evaluated at room temperature and at $2-4{ }^{\circ} \mathrm{C}$ for short term and long term stabilities. The above stability experiments were compared with freshly prepared solution and freshly spiked samples at the same concentration.

\section{Application to pharmacokinetic study}

Forty eight healthy male subjects who gave written informed consent took part in this study. During screening subjects with health problem, drug or alcohol abuse and abnormalities in laboratory screening were excluded in enrollment of the study. This study was approved by ethics committee on clinical investigation and was performed according to the rules of good clinical practice. After an overnight fast, all subjects were given alverine citrate $60 \mathrm{mg}$ oral capsule. Blood samples were collected via cannula before and after admission. The blood samples were immediately centrifuged at $5000 \mathrm{rpm}$ for $10 \mathrm{~min}$ at $4{ }^{\circ} \mathrm{C}$ and the plasma samples were stored at $-20{ }^{\circ} \mathrm{C}$ until LC-MS-MS analysis. Pharmacokinetic parameters were calculated by a non-compartmental analysis using WinNonlin software (Version 5.2, Pharsight Corp., Mountain View, CA, USA). The peak plasma concentration $\left(\mathrm{C}_{\max }\right)$ and time to reach $C_{\max }\left(T_{\max }\right)$ were observed directly from the experimental data, while $\mathrm{AUC}_{0-\mathrm{t}}$ and $\mathrm{AUC}_{0 \text {-inf }}$ was calculated using trapezoidal rule-extrapolation method.

\section{Results and Discussion}

\section{Mass spectrometry}

In the positive ion mode, both ALV and MHA gave protonated molecular ions, $[\mathrm{M}+\mathrm{H}]^{+}$, as the major species. The fragmentation patterns of the protonated molecular ions were evaluated by increasing the collision energy. The product ion spectra and fragmentation patterns for ALV, MHA and IS are shown in Figures 2, 3 and 4 respectively, where the greatest intensity was observed at $m / z 91.11$ for ALV, $m / z, 106.90$ for MHA and $m / z 86.00$ for IS, respectively. The mass parameters were optimized by observing the maximum response of the product ions.

\section{Chromatography}

To optimize chromatographic condition, many columns, i.e $\mathrm{C} 18, \mathrm{C} 8$ and $\mathrm{CN}$ columns and various compositions of mobile phases which show good resolution and symmetric peak shape of analytes as well as suitable retention times were examined. Thus, Hypersil Gold $\mathrm{C} 18(50 \times 4.6 \mathrm{~mm}, 5 \mu$ particle size $)$ column and an isocratic mobile phase consisting of $5 \mathrm{mM}$ ammonium formate $(\mathrm{pH} 3.5)$ and acetonitrile in a ratio 15:85 (v/v) gave good peak shape and response. Under the optimum conditions, analytes and IS were free of interference from endogenous substances and typical intra-batch retention time for ALV, MHA and IS were $2.06,1.90$ and 2.09 respectively. 


\section{Sample preparation}

Initially, solid phase extraction was investigated on API 5000 LC-MS-MS with LLOQ $0.1 \mathrm{ng} / \mathrm{mL}^{8}$. Aim of this work was to develop and validate a simple, rapid and more sensitive assay method up to LLOQ $0.060 \mathrm{ng} / \mathrm{mL}$ on API 4000 LC-MS-MS and its application towards determination of pharmacokinetics of ALV and MHA in clinical studies. During method development different extraction procedures and chromatographic conditions were carried for evaluation of analytes and IS. No significant response was observed in liquidliquid and protein precipitation extraction methods. For SPE different make of cartridges were tested. Finally, oasis cartridge HLB $1 \mathrm{cc} 30 \mathrm{mg}$ was selected for current assay as it was found to be reproducible and gave good recovery with less batch to batch variation when compared with other make of cartridges. Electro spray ionization (ESI) with positive ion mode, evaluated to get better response of analytes and IS. An isocratic mobile phase consisting of $5 \mathrm{mM}$ ammonium formate $(\mathrm{pH} 3.5$ ) buffer and acetonitrile resulted in improved signal. The flow rate for analysis was optimized at $0.4 \mathrm{~mL} / \mathrm{min}$ with a reduced runtime of $3.5 \mathrm{~min}$, resulting in good peak shape with higher output.

\section{Method Validation}

\section{Selectivity}

Six lots of blank human plasma and one each of lipemic and heamolysed plasma extracts from different sources were analyzed. Representative chromatograms obtained from blank plasma and plasma spiked with LLOQ standard for ALV and MHA respectively is presented in Figures 5 and 6 respectively. Due to high specificity of MS-MS detection, no interfering or late eluting peaks were observed at retention time of each analyte and IS.
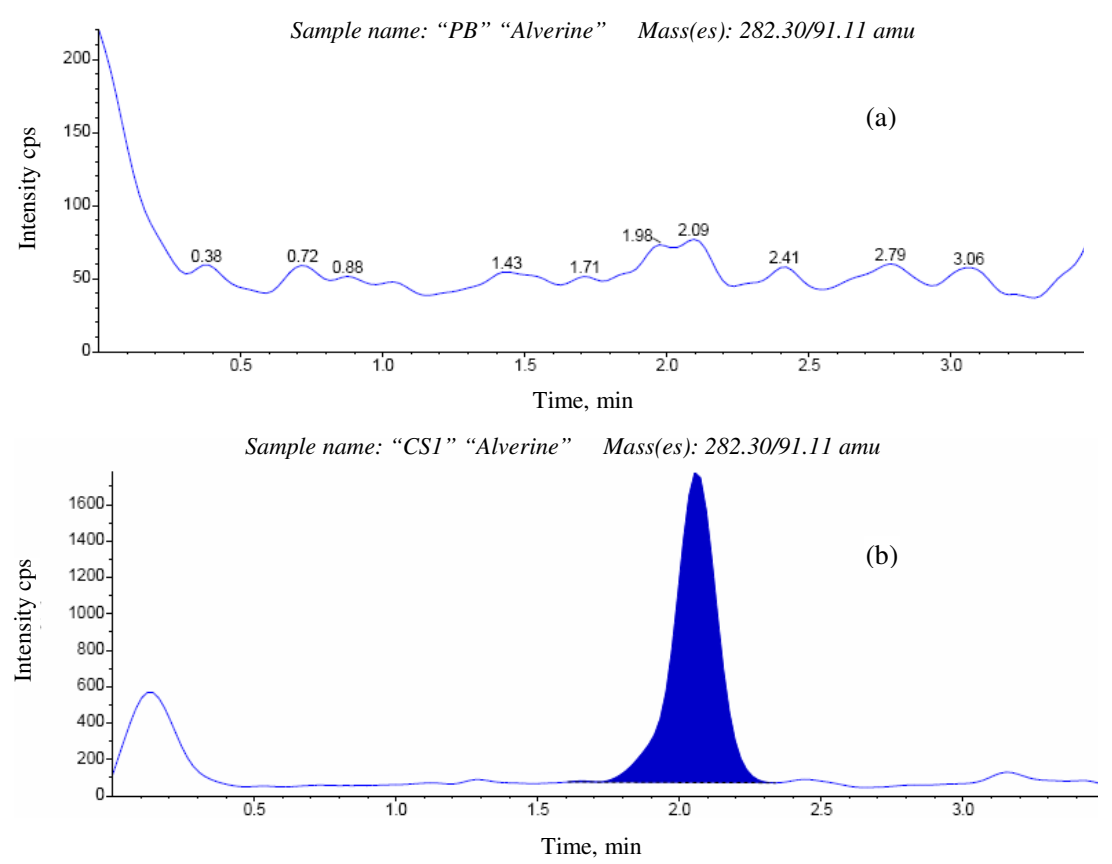

Figure 5. MRM chromatograms obtained from human plasma blank (a) and plasma spiked (b) with ALV at lower limit of quantification $(0.060 \mathrm{ng} / \mathrm{mL})$ 


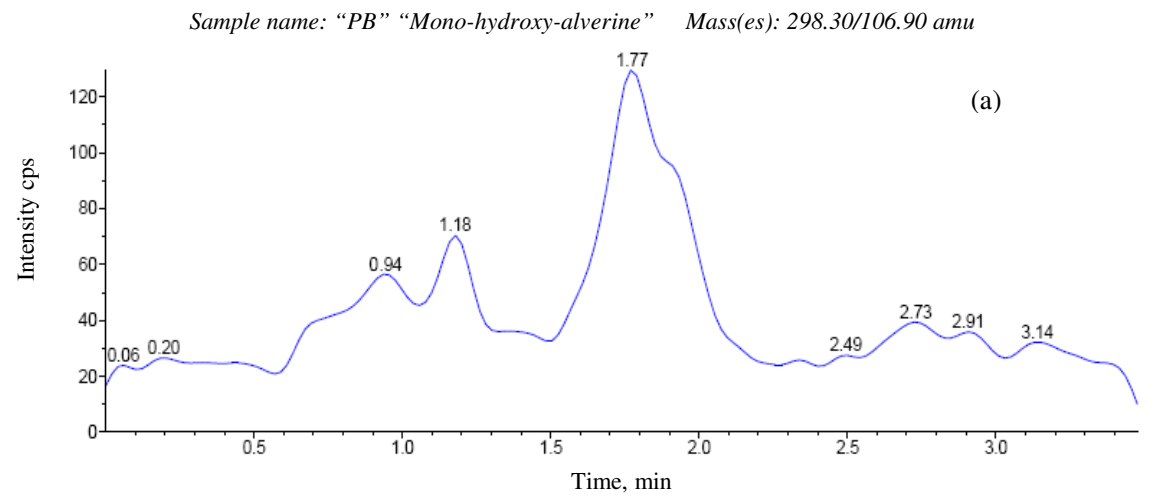

Sample name: "CS1" "Mono-hydroxy-alverine" Mass(es): 298.30/106.90 amu

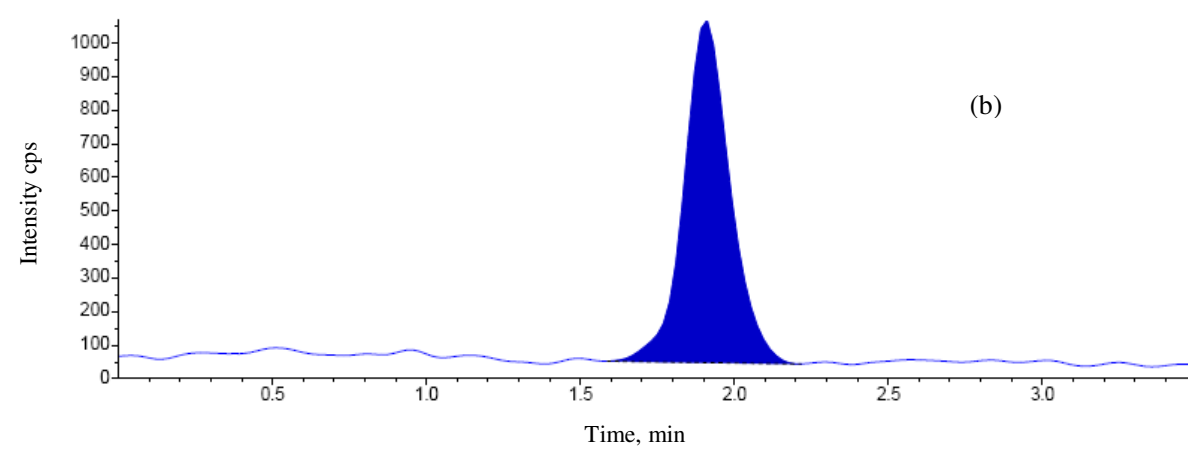

Figure 6. MRM chromatograms obtained from human plasma (a) blank and (b) plasma spiked with MHA at lower limit of quantification $(0.060 \mathrm{ng} / \mathrm{mL})$

\section{Linearity and $L L O Q$}

The calibration curve for human plasma provided reliable response for ALV and MHA from 0.060 to $10 \mathrm{ng} / \mathrm{mL}$. The best linear fit and least squares residuals for the calibration curve were achieved with $1 / \mathrm{x}^{2}$ weighing factor. The mean correlation coefficient during the validation was 0.9988 for ALV and 0.9983 for MHA in human plasma. The calibration obtained as described above was suitable for the quantification of ALV and its active metabolite, MHA in human plasma.

The LLOQ validated for both ALV and MHA was $0.060 \mathrm{ng} / \mathrm{mL}$ in human plasma. After the application of above described method, it was possible to detect the concentrations up to $0.010 \mathrm{ng} / \mathrm{mL}$ in subject samples for both ALV and MHA. The concentrations below LLOQ in subject samples were excluded from statistical analysis.

\section{Precision and accuracy}

The data of intra-day and inter-day precision and accuracy for the method were summarized in Table 1 . This intra and inter day assay was determined by analyzing six replicates of each QC samples on different days. The intra-day precision range was from 4.32 to $7.97 \%$ for ALV and 4.03 to $9.78 \%$ for MHA. The inter-day precision range was 5.65 to $9.18 \%$ for ALV and 4.96 to $8.44 \%$ for MHA, respectively. The intra- and inter-day accuracies were within range for both ALV and MHA. 
Table 1. Results from assessment of the accuracy and precision of the method

\begin{tabular}{|c|c|c|c|c|c|c|c|}
\hline \multirow[b]{2}{*}{ Compound } & \multirow{2}{*}{$\begin{array}{c}\text { Nominal } \\
\text { Concentration, } \\
\mathrm{ng} / \mathrm{mL}\end{array}$} & \multicolumn{3}{|c|}{ Intra-day $(n=6)$} & \multicolumn{3}{|c|}{ Inter-day $(n=6)$} \\
\hline & & $\begin{array}{l}\text { Concentration } \\
\text { tested, } \mathrm{ng} / \mathrm{mL}\end{array}$ & $\begin{array}{c}\mathrm{CV} \\
\%\end{array}$ & $\begin{array}{c}\mathrm{RE}, \\
\%\end{array}$ & $\begin{array}{l}\text { Concentration } \\
\text { tested, } \mathrm{ng} / \mathrm{mL}\end{array}$ & $\begin{array}{c}\mathrm{CV} \\
\%\end{array}$ & $\mathrm{RE}$ \\
\hline \multirow{5}{*}{ ALV } & 0.062 & 0.063 & 4.96 & 1.61 & 0.065 & 6.47 & 4.84 \\
\hline & 0.184 & 0.199 & 7.67 & 8.15 & 0.197 & 7.97 & 7.07 \\
\hline & 5.097 & 5.508 & 5.26 & 8.06 & 5.195 & 4.32 & 1.92 \\
\hline & 7.646 & 8.181 & 9.18 & 7.00 & 8.231 & 5.13 & 7.65 \\
\hline & 10.195 & 10.961 & 5.20 & 7.51 & 10.934 & 5.65 & 7.25 \\
\hline \multirow{5}{*}{ MHA } & 0.066 & 0.074 & 3.49 & 12.12 & 0.072 & 5.12 & 9.09 \\
\hline & 0.199 & 0.216 & 8.13 & 8.54 & 0.208 & 9.78 & 4.52 \\
\hline & 5.519 & 6.165 & 4.96 & 11.71 & 6.214 & 4.41 & 12.59 \\
\hline & 8.278 & 8.628 & 8.44 & 4.23 & 8.790 & 4.80 & 6.19 \\
\hline & 10.983 & 10.964 & 4.03 & -0.17 & 11.024 & 5.62 & 0.37 \\
\hline
\end{tabular}

Extraction recovery and matrix effect

The extracted recoveries of ALV, MHA and IS from human plasma, are listed in Table 2. The mean (overall recovery) recoveries of ALV, MHA and IS were $37.72 \%$ (precision $4.76 \%$ ), $41.67 \%$ (precision $5.89 \%$ ) and $35.59 \%$ (precision $11.27 \%$ ), respectively. The \%RSD for matrix effect were all observed between-in acceptance criteria, which means either ionization suppression or enhancement from the plasma matrix was negligible for this method.

Table 2. Recovery of ALV and MHA $(n=6)$

\begin{tabular}{cccc}
\multicolumn{4}{c}{ Table 2. Recovery of ALV and MHA $(n=6)$} \\
\hline Compound & Concentration, $\mathrm{ng} / \mathrm{mL}$ & Mean, $\%$ & RSD, \% \\
\hline \multirow{2}{*}{ ALV } & 0.184 & 37.05 & 8.01 \\
& 5.097 & 36.27 & 3.42 \\
& 7.646 & 39.85 & 2.84 \\
MHA & 0.199 & 43.96 & 10.25 \\
& 5.519 & 40.46 & 5.87 \\
IS & 8.278 & 40.59 & 1.54 \\
\hline
\end{tabular}

\section{Stabilities}

All the stability experiments were investigated at lower and higher quality control levels. The results reveal that the ALV and MHA are stable in human plasma under following conditions i.e. bench-top stability $24 \mathrm{~h}$, auto-sampler stability $24 \mathrm{~h}$, dry extract stability $24 \mathrm{~h}$ and coolant stability $24 \mathrm{~h}$. The stability of plasma samples exposed to freezing and thawing before analysis was tested by extracting and analyzing LQC and HQC samples after three freeze-thaw cycle. ALV and MHA were stable for at least 94 days, when spiked human plasma samples were frozen at $-20{ }^{\circ} \mathrm{C}$. Long term stability data generated was sufficient enough as it covers the entire study period right from the collection of blood samples to final date of analysis. The above stability experimental results revealed that no significant degradation occurred during chromatography, extraction and sample storage processes for ALV and MHA human plasma samples. It was also observed that stock solutions of ALV, MHA and IS in methanol were stable for 40 days at $2-4{ }^{\circ} \mathrm{C}$.

\section{Application}

The proposed validated method was successfully applied to the samples of reference and test formulation of alverine citrate $60 \mathrm{mg}$ capsule in a randomized, single dose, two treatment, two sequence, replicate, four period crossover pivotal bioequivalence study in 48 healthy, adult, male, human subjects under fasted condition. All samples including the calibration, 
QC and volunteer samples were run and analyzed in 36 days and precision and accuracy for calibration and QC samples were within acceptable limits. The chromatograms for ALV, MHA and IS in real subject samples are presented in Figures 7 and 8. The 90\% confidence interval of ALV for log transformed ratio of test/reference was within the range of $75-133 \%$ for $\mathrm{C}_{\max }$ (Maximum observed peak plasma concentration) and $80-125 \%$ for $\mathrm{AUC}_{0-\mathrm{t}}$ (Area Under Curve till last measurable concentration) and $\mathrm{AUC}_{0-\infty}$ (Area under Curve till infinity). Mean plasma concentrations versus time profile for ALV and MHA under fasted condition are presented in Figures 9 and 10.
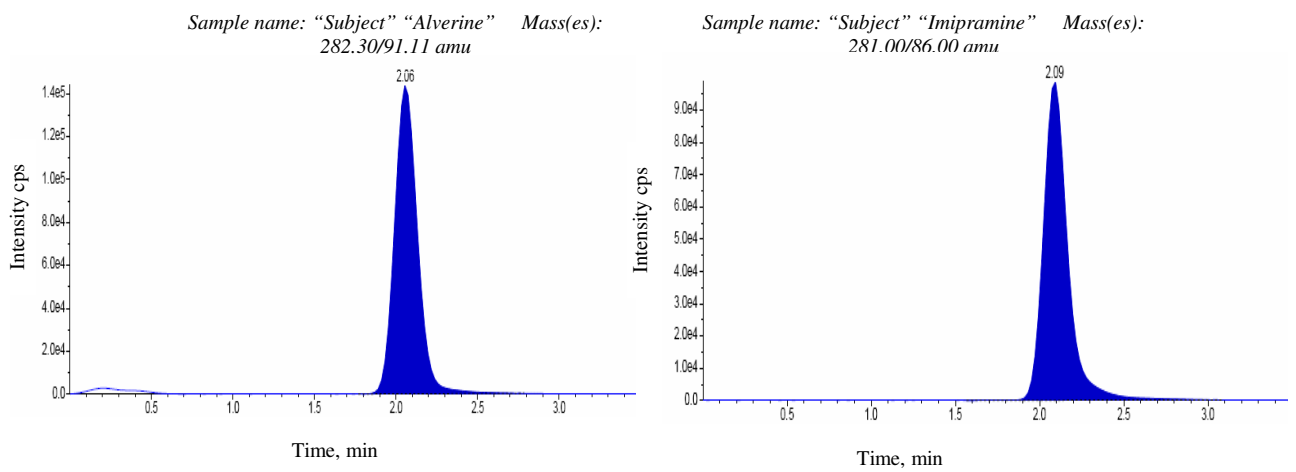

Figure 7. Representative chromatograms of subject sample for ALV spiked with IS
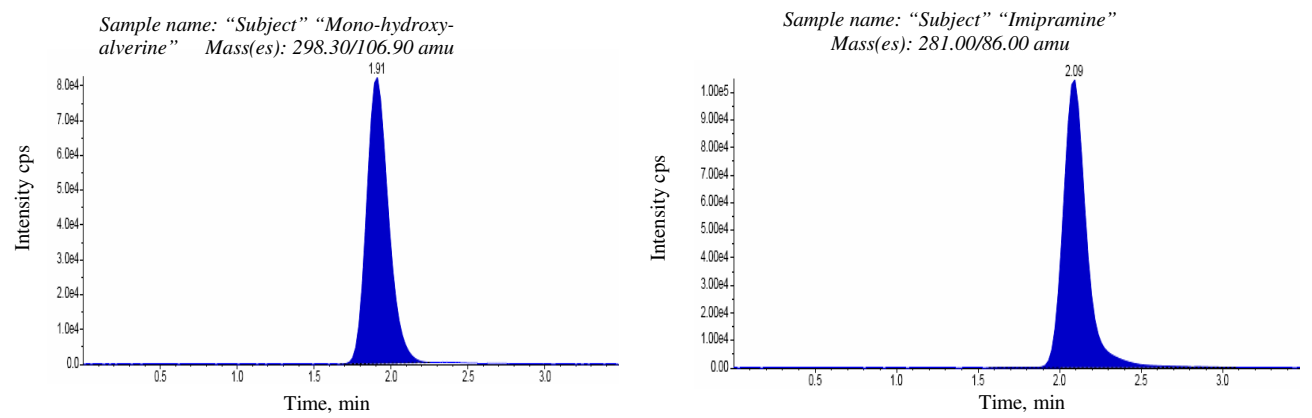

Figure 8.. Representative chromatograms of subject sample for MHA spiked with IS

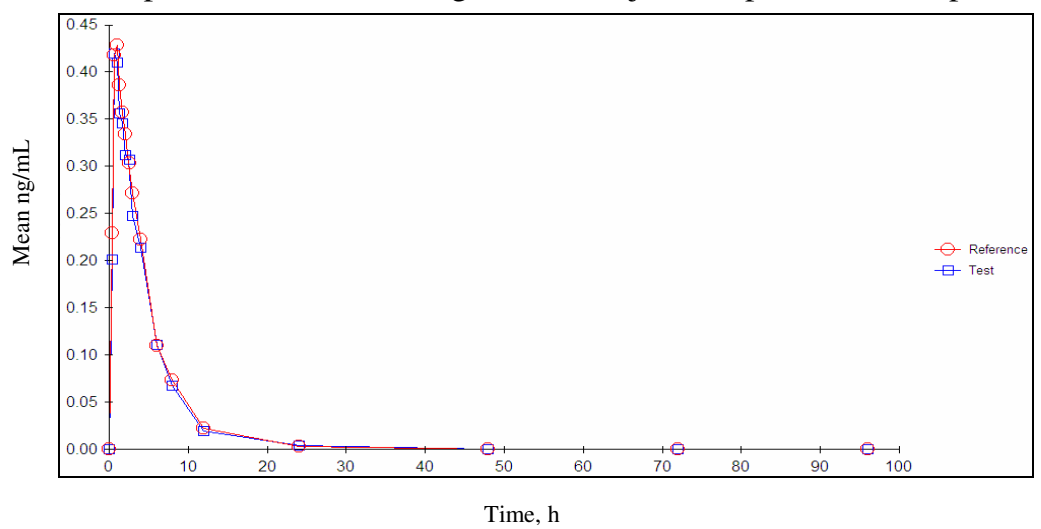

Figure 9. Mean plasma drug concentration -time profile for ALV in healthy volunteers after a single oral dose of $60 \mathrm{mg}$ ALV capsule $(n=48)$ 


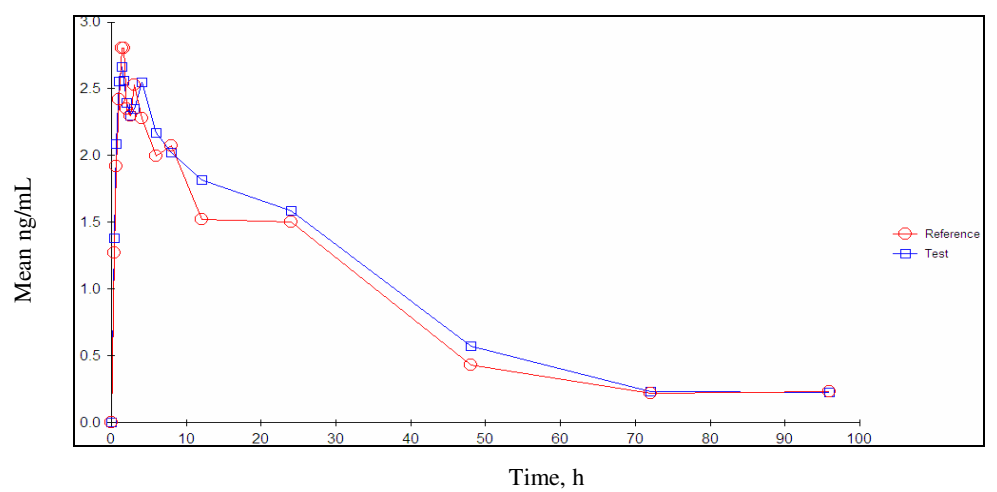

Figure 10. Mean plasma drug concentration -time profile for MHA in healthy volunteers after a single oral dose of $60 \mathrm{mg} \mathrm{ALV}$ capsule $(n=48)$

\section{Conclusion}

A selective, sensitive, reproducible and fully validated API 4000 LC-MS-MS method is reported for the determination of ALV and its active metabolite in human plasma. There is only one reported article on estimation of ALV and PHA with lower limit of quantification up to $0.1 \mathrm{ng} / \mathrm{mL}$ on API $5000 \mathrm{LC}-\mathrm{MS}-\mathrm{MS}$.

We report, the above discussed method with more sensitivity (LLOQ) upto $0.060 \mathrm{ng} / \mathrm{mL}$ on API 4000 LC-MS-MS with run time of $3.5 \mathrm{~min}$. With this validated method it was also possible to detect concentrations from subject samples upto $0.010 \mathrm{ng} / \mathrm{mL}$ for both ALV and MHA, which is sufficient enough to give data for calculating pharmacokinetic data and establish bioequivalence. This method requires only $0.5 \mathrm{~mL}$ of biological sample and owing to the simple sample preparation and short run time of $3.5 \mathrm{~min}$, it allows high sample throughput.

\section{Acknowledgment}

The authors are indebted to Dr. Ajit Padgaonkar, Directors, Mr. Nelson Varghese (Head of the quality assurance department) and Mr. Sudhir Pawar (Biostatistician) for their continuous support and encouragement. The authors gratefully acknowledge Drug Monitoring Research Institute, India for providing the necessary laboratory facilities required for this work.

\section{Reference}

1. Alverine (371), The Merck Index, $14^{\text {th }}$ Ed., p.63.

2. Hayase M, Hashitani H, Suzuki H, Kohri K and Brading A F, Br J Pharm., 2007, 152, 1228-1238.

3. Bouvier M, Grimaud J C, Abysique A and Chiarelli P, Gastroenterol Clin Biol., 1992, 16, 334-348.

4. Abysique A, Lucchini S, Orsoni P, Mei N and Bouvier M, Aliment Pharm Ther., 1999, 13, 561-566.

5. Coelho A M, Jacob L, Fioramonti J and Bueno L, J Pharm Pharm., 2001, 53(10), 1419-1426.

6. Mitchell S A, Mee A S, Smith G D, Palmer K R and Chapman R W, Aliment Pharmacol Ther., 2002, 16(6), 1187-1195.

7. Arhan M, Koklu S, Koksal A S, Yolcu O F, Koruk S, Koruk I and Kayacetin E, World J Gastroenterol, 2004, 10(15), 2303-2304.

8. Noel A G, Avdhoot L, Ashutosh P, Santosh S J, Vikas V V and Jayram A T, J Chromatogr B, 2009, 877(3), 197-206.

9. Guidance for Industry: Bioanalytical Method Validation, U.S. Department of Health and Human Services, Food and Drug Administration Centre for Drug Evaluation and Research (CDER), Centre for Veterinary Medicine (CVM), May 2001. 


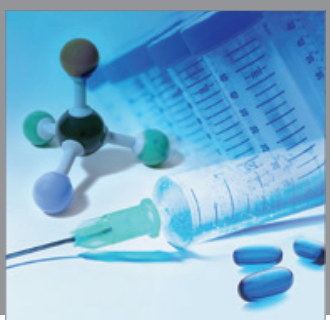

International Journal of

Medicinal Chemistry

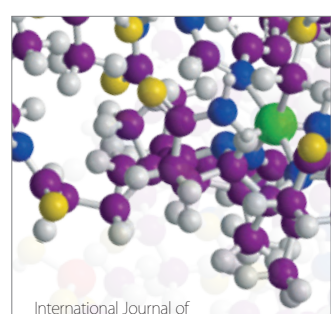

Carbohydrate Chemistry

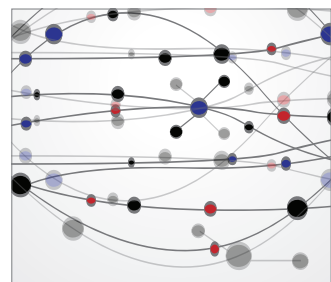

The Scientific World Journal
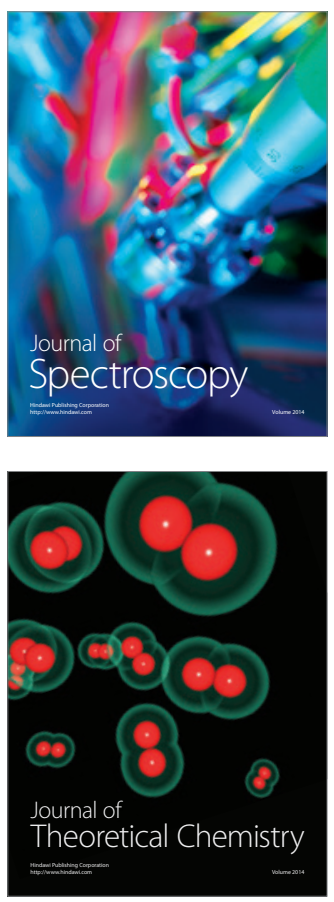
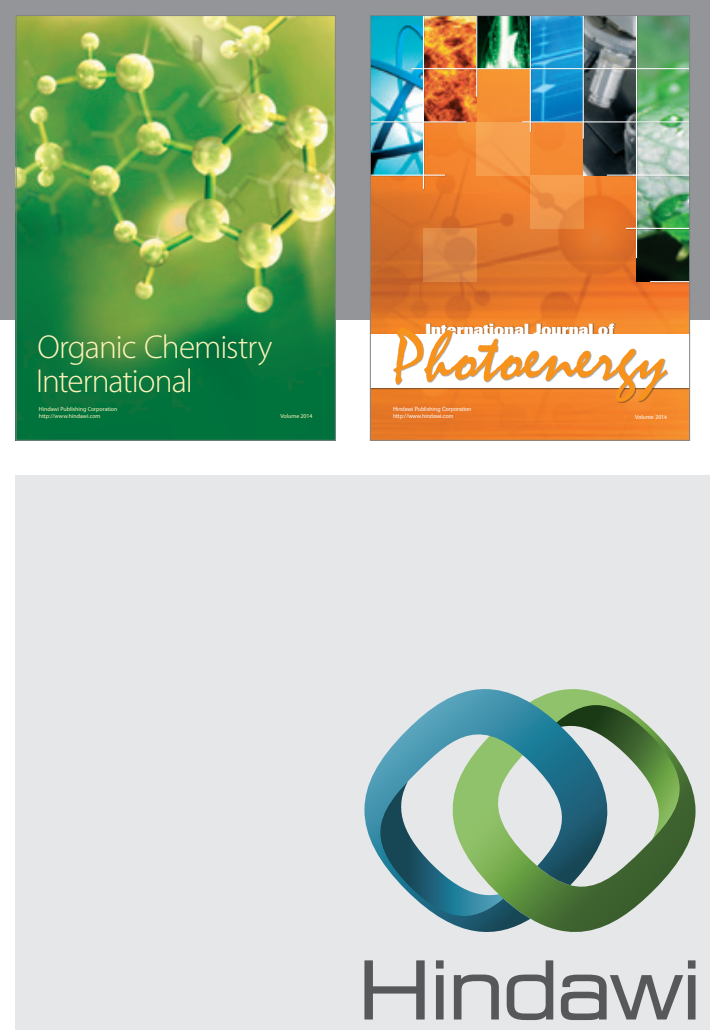

Submit your manuscripts at

http://www.hindawi.com
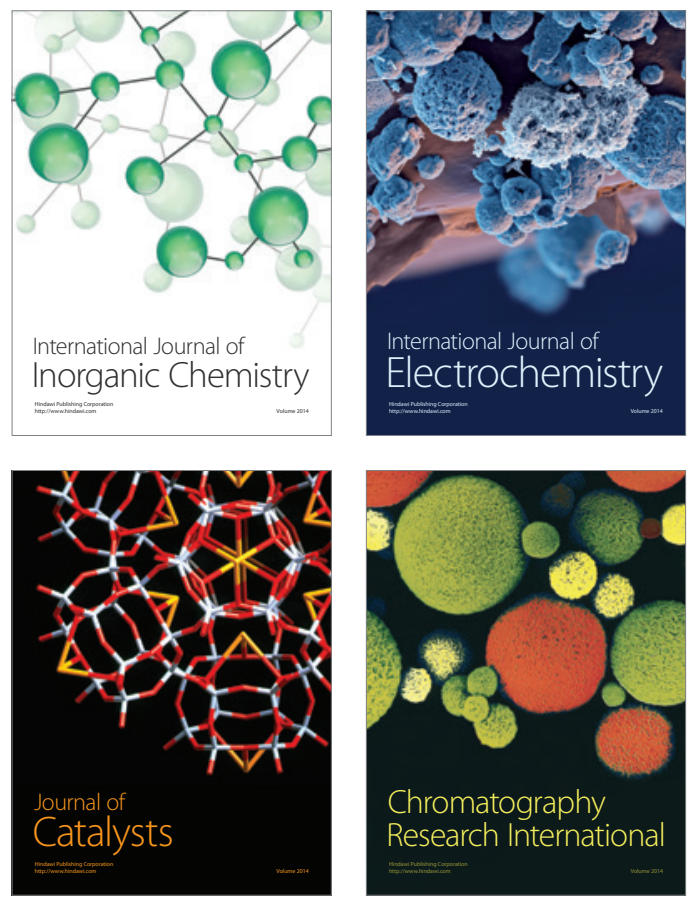
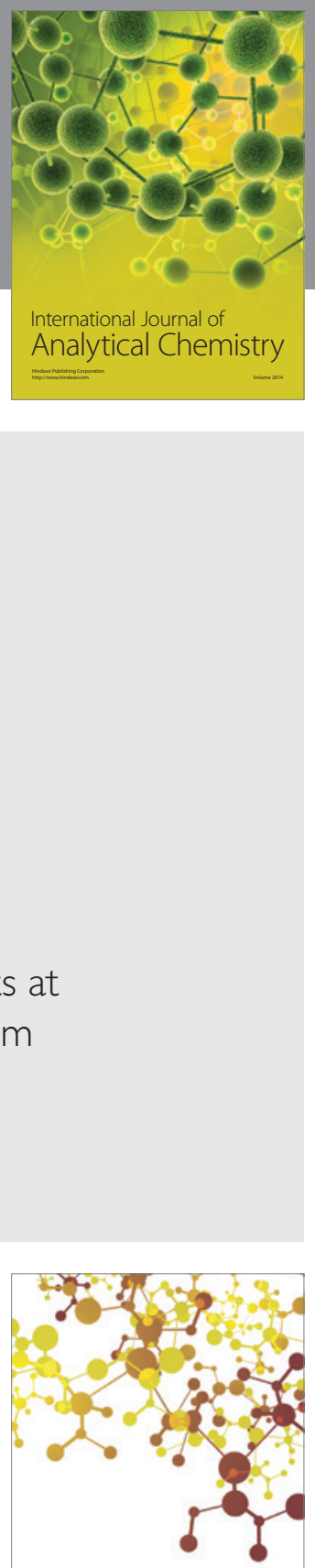

Journal of

Applied Chemistry
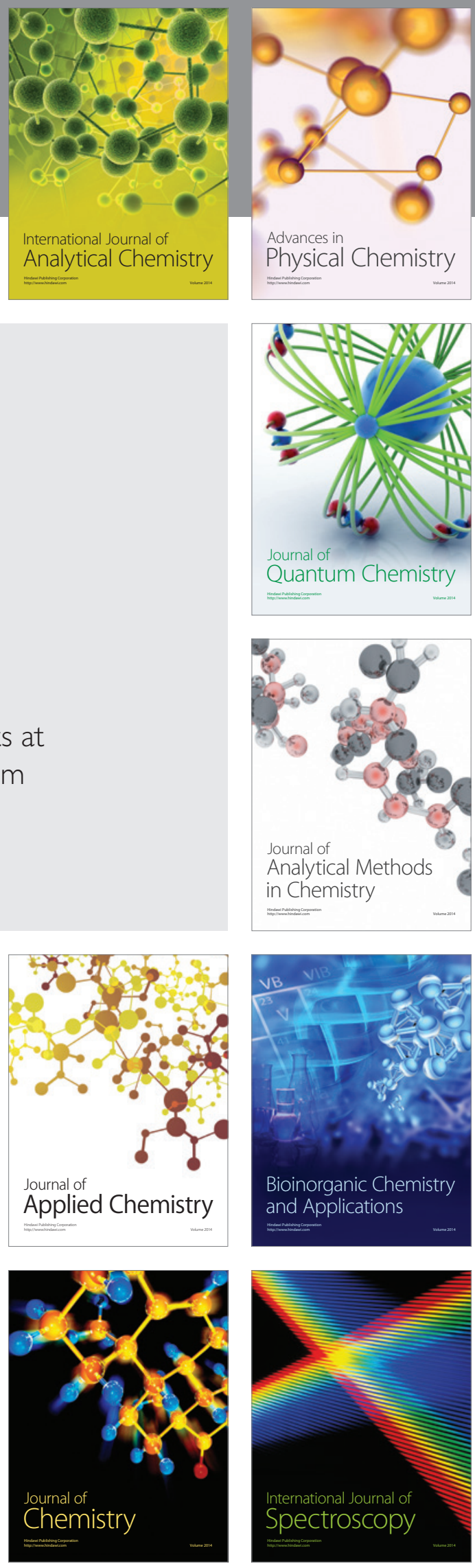